\title{
Mother's views and perceptions regarding breast feeding as seen in a group of Sri Lankan mothers
}

\author{
T C Weerasuriya ${ }^{1}$, W M S P Weerasuriya ${ }^{1}$, L T Wijeratne ${ }^{1}$, T N B Wijesinghe ${ }^{1}$
}

Sri Lanka Journal of Child Health, 2001; 30: 37-40

(Key words: breast feeding, mother's views)

\begin{abstract}
The aim of the study was to study the views and perceptions of a group of mothers regarding breastfeeding.

The study was done in the professorial unit of the de Soysa Maternity Hospital (DMH). The study involved 50 mothers. A pre-tested questionnaire was used to get the information.

In spite of the improvement of attitudes and views regarding breast feeding, it was found that a considerable number of mothers still harbor unsubstantiated views and unhealthy perceptions regarding breast-milk and breast-feeding.
\end{abstract}

\section{Introduction}

If poverty, malnutrition and infection were the three heads of the same dragon, then, breast- feeding would be St. George's sword to slay that evil dragon.

Breast milk is a cheap and effective way of combating several childhood problems, especially prevalent in developing countries.

\section{Objectives}

The main objective of this study was to study the views and perceptions of mothers regarding breast-feeding and breast milk. In addition, details regarding the source of information of proven facts regarding breast-feeding were also assessed.

\section{Method}

The study was conducted in wards 03 and 15 in the De Soysa Maternity Hospital (DMH), on the 07th of December 1995. A questionnaire was used to get the required information. The questionnaire was pre-tested on a group of mothers (10 mothers in $\mathrm{DMH})$. The questionnaire was self-administered and the members of the study group were available to do clarifications wherever necessary. All clarifications were standardized, ensuring uniformity.
A count was maintained, starting from bed number 01 of ward 03 of the $\mathrm{DMH}$, and when the count reached 50 , the process was stopped.

\section{Results}

Out of the mothers who participated $88 \%$ were Sinhalese and $6 \%$ were Tamil (Table 1).

Table 1

\section{Ethnicity}

\begin{tabular}{|l|c|}
\hline \multicolumn{1}{|c|}{ Ethnicity } & $\%$ \\
\hline Sinhala & 88 \\
\hline Tamil & 06 \\
\hline Muslim & 04 \\
\hline Burgher & 00 \\
\hline Other & 02 \\
\hline Total & 100 \\
\hline
\end{tabular}

Seventy two percent were Buddhists and 14\% were Roman Catholics (Table 2).

Table 2

Religion

\begin{tabular}{|l|c|}
\hline \multicolumn{1}{|c|}{ Religion } & $\%$ \\
\hline Buddhist & 72 \\
\hline Hindu & 04 \\
\hline Roman Catholic & 14 \\
\hline Christian & 04 \\
\hline Islam & 06 \\
\hline Total & 100 \\
\hline
\end{tabular}

Six percent of the mothers were illiterate, $4 \%$ had received university education and $60 \%$ had received secondary school education (Table 3 ).

Table 3

Level of Education

\begin{tabular}{|l|c|}
\hline \multicolumn{1}{|c|}{ Level of Education } & $\%$ \\
\hline Illiterate & 06 \\
\hline Non-formal & 00 \\
\hline Primary only & 30 \\
\hline Secondary & 60 \\
\hline University & 04 \\
\hline Total & 100 \\
\hline
\end{tabular}


A monthly income of $<1500 /=$ rupees per month was seen among $6 \%$ and an income of $3000-5000 /=$ per month was seen in $32 \%$ (Table 4 ).

Table 4

Monthly income

\begin{tabular}{|l|c|}
\hline $\begin{array}{c}\text { Monthly income in } \\
\text { Rupees /Month }\end{array}$ & $\%$ \\
\hline$<1500.00$ & 06 \\
\hline $1500.00-3000.00$ & 22 \\
\hline $3000.00-5000.00$ & 32 \\
\hline $5000.00-8000.00$ & 22 \\
\hline$>8000.00$ & 18 \\
\hline Total & 100 \\
\hline
\end{tabular}

There were 24 mothers who had breast-fed their children before, while 26 were yet to experience breastfeeding. The median duration of breast -feeding among the mothers, who had breast-fed before, was 10 months. All the mothers thought that every child should be breast-fed and every one knew that breast milk provides nutrition to the baby. Only $64 \%$ of the mothers knew that breast-milk should be exclusively fed for four months. Only $8 \%$ of the mothers had gained this information from the antenatal clinic. Thirty eight percent of the mothers had gained this information from an elder in the family (Table 5).

Table 5

Source of information regarding the duration of exclusive breast-feeding in the mothers who responded correctly

\begin{tabular}{|l|c|}
\hline $\begin{array}{c}\text { Source of information on } \\
\text { exclusive breast-feeding }\end{array}$ & $\%$ \\
\hline Doctor & 26 \\
\hline Other health worker & 22 \\
\hline School & 10 \\
\hline Newspaper & 32 \\
\hline TV & 18 \\
\hline Radio & 12 \\
\hline Leaflets & 08 \\
\hline Elders in the family & 38 \\
\hline Antenatal clinics & 08 \\
\hline
\end{tabular}

Regarding the total duration of breast-feeding, 56\% of the mothers thought that the child should be breast-fed until the child refuses to drink breast milk any more (Table 6).

Table 6

Duration of breast-feeding

\begin{tabular}{|c|c|}
\hline Number of months & $\%$ \\
\hline 01 & 00 \\
\hline 03 & 02 \\
\hline 06 & 04 \\
\hline $06-12$ & 00 \\
\hline 12 & 12 \\
\hline$>12$ & 22 \\
\hline Until child refused & 56 \\
\hline No idea & 04 \\
\hline
\end{tabular}

Eighteen percent of the mothers thought that colostrum should not be given to the baby. Out of the mothers studied $62 \%$ thought that the mother should consume a large volume of fluids before breastfeeding the baby. Twenty percent thought that breastfeeding produces adverse effects on their figure (Table 7).

$56 \%$ of the mothers knew that even if they are suffering from a minor illness they could continue to feed their baby on breast-milk. $84 \%$ knew that by breast-feeding the child it is possible to gain benefits other than nutrition to the child. Only 64\% were aware that by breast-feeding the baby one might not conceive a second time during the period of breastfeeding. $4 \%$ of mothers had gained this information from the antenatal clinic, whereas $22 \%$ had obtained it from an elder in the family (Table 8).

The mean duration of lactational-amenorhoea was four months, among the mothers who had previous experience of breast-feeding. 


\section{Table 7 Perceptions of mothers regarding breast-milk and breast-feeding}

Statement

Colostrum should be given to the baby

A large volume of fluid should be taken before breastfeeding

Breast-feeding has adverse effects on one's figure

Formula-milk is more nutritious than breast-milk
Yes $\%$

74

62

20

72

08

02

94

04

When the baby is ill you should not breast-feed the child

No $\%$

18

22

16

84

06

When you are suffering from a common cold, fever, diarrhoea you should not breast-feed the baby.

38

56

06

\section{Table 8 Source of information regarding the knowledge of lactational amenorrhoea}

Source of information regarding lactational amenorrhoea

Doctor

Other health workers

School

Newspapers

Leaflets

TV

Radio

Elders in the family

Antenatal clinics

\section{Discussion}

In this study it was noted that the median duration of breast-feeding among mothers was 10 months. All the mothers thought that breast-milk should be given to every child and all of them knew that breast-milk is nutritious to the baby. In a similar study done in Kandy in 1980, it was found that only $70 \%$ of the mothers thought that breast milk is nutritious to the child $^{1}$.

Sixty four percent of the mothers knew that breastmilk should be exclusively fed for four months. In a study done in the plantation sector in 1998 only
$32.4 \%$ of the mothers exclusively breast-fed their babies ${ }^{2}$.

Only $8 \%$ of the mothers had gained information regarding exclusive breast-feeding from our antenatal clinic. In the study done in Kandy, only $2 \%$ of the mothers had gained this information from an antenatal clinic ${ }^{1}$.

$38 \%$ had gained this information from an elder in the family whereas in the study done in Kandy, only 5\% got this information from an elder in the family ${ }^{1}$. 
In spite of the health education given to the mothers, $18 \%$ of the mothers still thought that colosturm should not be given to the baby.

Myths such as, a large volume of fluids should be consumed by the mother before breast-feeding the baby; breast-feeding produces adverse effects on the figure of the mother; and cows milk is more nutritious to the baby than breast-milk are still harbored by the mothers.

$84 \%$ knew that by breast-feeding the child it is possible to gain benefits other than nutrition to the child. Additional benefits such as protection against diarrhoeal diseases and respiratory tract infections were clearly shown to be related to exclusive breastfeeding in a previous study in Sri Lanka ${ }^{3}$.

64\% knew about lactational-amennorhoea and only $4 \%$ had come to know about this from an antenatal clinic. $22 \%$ had obtained this information from an elder in the family. Mean duration of lactationalamennorhoea was 4 months among mothers with previous experience of breast- feeding.

In this study the professorial unit of one hospital in Colombo was used. The pregnant mothers attending this unit do not represent the whole population of pregnant mothers in our country. Hence the conclusions in this study cannot be applied to the whole country in general. More work perhaps, on a multi-centre basis would be required to assess the national picture.

\section{Conclusions}

In spite of the improvement in attitudes, knowledge and behaviour regarding breast-feeding a considerable number of mothers in Sri Lanka still harbor unsubstantiated views and unhealthy perceptions regarding breast-milk and breast-feeding. Further, the antenatal clinic had made a poor contribution toward a goal of keeping our mothers well informed regarding breast milk and breastfeeding

\section{Acknowledgements}

We wish to acknowledge Prof. H. R. Seneviratne's contribution to this study by allowing us to use his unit. We also wish to thank Prof. K. H. Thennakoon for guiding us, and Dr. Prasanna Cooray for helping us with the analysis. W. S. A. Vithanage, W. Wagasenevi, D. N. Walpola, W. A. T. I. Weerasinghe, W. S. Widhanapathirana, P. D. P. Wijegunawardene, K. J. Wijeyerathne, G. N. Wijesooriya, N. A. S. P. Wijerathne, W. D. G. S.Wijesekara, H. T. Wijesinghe, W. N. C. Wijesinghe, A. L. D. B. S. Wijesiri, H. P. P. Warnakulasooriya are acknowledged here for their help with the logistics.

\section{References}

1. Gunathilake L. Breast-feeding. A survey of mothers' attitudes, practices etc. Proc. Kandy $\mathrm{Cl}$. Soc. 1980; 3: 55-6.

2. Sorenson et al. Exclusive breast-feeding among women in the plantation sector of Sri Lanka. Journal of Tropical Pediatrics 1998; 44(5): 3135.

3. Perera BJC, Ganesan SI. The impact of breastfeeding practices on the respiratory and diarrhoeal diseases in infancy. Journal of Tropical Pediatrics 1999; 45(2): 115-8. 
